\title{
Marta e Maria no Getsêmani de Fra Angelico: luzes medievais na releitura de tradições e textos bíblicos
}

\author{
Martha and Mary in Fra Angelico's Agony in the Garden: medieval lights in \\ the rereading of Biblical traditions and texts
}

\author{
Ivoni Richter Reimer*
}

\begin{abstract}
Resumo
Apresentação e interpretação da obra artística Getsêmani do monge dominicano Fra Angelico como parte da história interpretativa do texto bíblico de Lucas 10,38-42 e das narrativas bíblicas que apresentam Jesus no Getsêmani com os discípulos Pedro, João e Tiago. O contexto histórico da obra é o da Baixa Idade Média, na Itália. Na pintura, Marta e Maria aparecem inseridas na história da Paixão de Jesus, no Getsêmani, como releitura contextualizada por Fra Angelico na história do seu tempo. Para análise, utilizam-se referenciais da hermenêutica feminista na interface com história da teologia, história cultural e história da arte. Objetiva-se demonstrar que a arte sacra cristã, como parte da história interpretativa, não apenas ilustra algo do passado e/ou do presente, mas também influencia a forma(ta)ção de mentalidades. Esta função pedagógica está presente e é interpretada no Getsêmani de maneira positiva em diálogo com movimentos de mulheres no contexto desta obra de arte. Observa-se que parte da história de mulheres está representada por meio da história interpretativa, presente também no afresco em questão. Hermeneuticamente, o texto, a imagem e a história interpretativa continuam desafiando as ciências, as competências e os movimentos libertários hodiernos.
\end{abstract}

Palavras-chave: Marta e Maria; hermenêutica; história de mulheres; Fra Angelico; Lucas 10

\begin{abstract}
Presentation and interpretation of the artistic work "Agony in the Garden" of the Dominican friar Fra Angelico as a part of the interpretative history of the Biblical text Luke 10.38-42 and of the Biblical narratives that present Jesus in the garden of Gethsemane together with the disciples Peter, John and James. The work's historical context is that of Italy in the Late Middle Ages. In the painting, Martha and Mary appear inserted into the story of the Passion of Jesus, in the garden of Gethsemane, as a rereading that Fra Angelico contextualized in the history of his time. For the sake of analysis, we used reference points from feminist hermeneutics at the interface of the theological, cultural and art history. We aimed at demonstrating that Christian sacred art, as a part of the interpretative history, not only illustrates something from the past and/or present, but has also some influence on the form(at)ing of mentalities. This pedagogical function is present and interpreted positively in the Agony in the Garden, in dialogue with women's movements in the context of this work of art. It can be noted that part of the women's story is represented by means of the interpretative history, also present in the fresco in question. Hermeneutically, the text, the picture and the interpretative history continue challenging today's sciences, skills and libertarian movements.
\end{abstract}

Keywords: Martha and Mary; hermeneutics; women's story; Fra Angelico; Luke 10.

\footnotetext{
Artigo recebido em 25 de junho de 2014 e aprovado em 11 de novembro de 2014.

* Doutora em Teologia. Professora da Pontifícia Universidade Católica de Goiás. País de origem: Brasil. E-mail: ivonirr@gmail.com. Quero expressar, aqui, minha gratidão a Haroldo Reimer pela leitura atenta e pelas sugestões bibliográficas. A Claude Detienne agradeço pela tradução de título, resumo e palavras-chave.
} 


\section{Preliminares com o Getsêmani}

Encontrei Marta e Maria no Getsêmani por ocasião de uma noite de insônia. Não foi durante os estudos de Teologia, nem durante o doutorado, nem tampouco em viagens de pesquisas realizadas durante vários anos de docência universitária. Havia entrado num sebo no centro de Goiânia, encontrei e comprei, em 2011, uma coleção intitulada Mestres da Pintura, editada e traduzida por Victor Civita (1978). Acostumei-me a folhear aleatoriamente algum volume à noite, antes de dormir. Naquela noite, peguei o volume com o nome de Fra Angelico, para mim desconhecido. Li um pouco do histórico, fiz as páginas dançarem sob o movimento de meus dedos, e deparei-me com a imagem número 54: a cena de Jesus no Getsêmani. O que me chamou a atenção e me fez parar de folhear não foi a cena do Getsêmani em si, a qual já vira representada artisticamente em outros lugares e cuja narrativa bíblica me era conhecida. Parei de folhear por causa de duas mulheres na margem direita inferior da obra, as quais tinham auréolas e nelas estavam escritos seus nomes. E olhando, divagando, adormeci.

Passou o tempo, outros compromissos fizeram aquela imagem ser substituída por outras, até que recebi o convite para fazer uma conferência num evento acadêmico, para o qual resolvi debruçar-me sobre a narrativa de Lucas 10,38-42, visto estar estudando o evangelho de Lucas e o evento tratar de relações de gênero e hermenêutica. Adentrei espaços antes nunca imaginados: fiquei fascinada não apenas com a exegese, mas também com a história interpretativa e efeitual daquele texto, que ficou marcada no imaginário e nas representações acerca de mulheres e suas funções. Foi nesta aventura exegético-hermenêutica que conheci parte da Legenda Áurea, de Jacobus de Voragine (Tiago de Voragine), uma coletânea de narrativas hagiográficas reunidas no século XIII, que apresenta também uma tradição popular francesa acerca de Marta e Maria. ${ }^{1} \mathrm{E}$ foi neste contexto que me lembrei daquela imagem que havia visto nos Mestres da Pintura,

\footnotetext{
${ }^{1}$ Algumas informações a este respeito, com referências, estão reunidas em Richter Reimer (2011).
} 
de Fra Angelico, porque nas auréolas daquelas duas mulheres constavam os nomes Sancta Marta e Sancta Maria. Lembrei, procurei e encontrei.

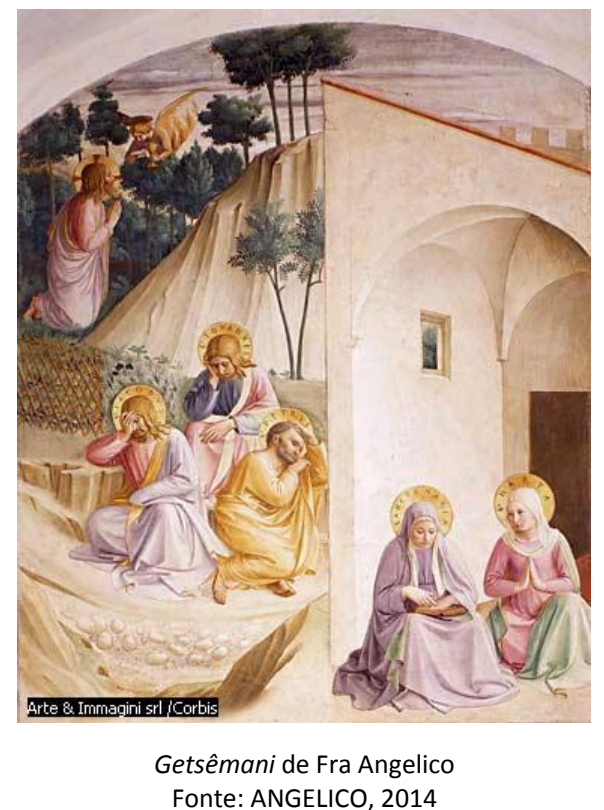

Vasculhei aquele livro em busca de informações acerca da imagem. Nada encontrei exceto o que consta na Nota das Pranchas, sob o número 54 (CIVITA, 1978, p. 29): “Oração no Horto - Afresco. Museu de São Marcos, Florença. Situado na cela n. ${ }^{\circ} 34$ do dormitório”. Li novamente a parte informativa do livro e encontrei algumas informações acerca do convento de São Marcos, em Florença, agora museu. Tratava-se de um convento dominicano ${ }^{2}$ que havia sido remodelado, em 1436, pela família Medici, sendo que Fra Angelico recebera a incumbência de pintar os corredores e as celas (quartos) dos seus irmãos religiosos, obra inaugurada em 1442, na presença do papa Eugênio IV.

Sabia, portanto, que se tratava de um afresco3 pintado na parede de uma cela de um monge dominicano, entre os anos 1430-40, em Florença, Itália. A pergunta que me fiz foi óbvia para quem interpreta textos bíblicos em perspectivas

\footnotetext{
${ }^{2}$ Acerca da ordem dominicana deste período, ver Le Goff (2008) e, especificamente sobre mulheres teólogas e escritoras dominicanas, Régnier-Bohler (1990) e Forcades i Vila (2013).

${ }^{3}$ Um afresco representa uma das obras pictóricas mais resistentes na história da arte, desde a Antiguidade. Trata-se de pintar sobre uma massa colocada sobre um mural ou parede, com pigmentos geralmente de origem mineral ou vegetal.
} 
feministas: o que fazem estas mulheres na cena do Getsêmani? Quem foi Fra Angelico que transportou Marta e Maria para este espaço? O que poderia significar tal transposição para a história de mulheres nos séculos XIV-XV, período marcadamente de transição também na forma(ta)ção de mentalidades?

Colocava-se, portanto, o desafio de continuar a história interpretativa de Lc 10, especificamente com e a partir deste afresco, cujo tema apresenta parte da Paixão de Jesus, quando ele se retirou para o Jardim Getsêmani, para orar. Para tal, fiz uso de resultados exegético-hermenêuticos já trabalhados anteriormente, tive de pesquisar acerca do contexto histórico-cultural de Fra Angelico e da história de mulheres naquele contexto, buscando compreender possíveis enunciados e indicações por meio daquela obra de arte medieval.

\subsection{Decifrar a imagem: algumas aproximações}

Motivada, lancei-me ao trabalho iconográfico, na tentativa de descrever a imagem e buscar compreendê-la. 4 Nisto, o próprio livro que me abrira o horizonte interpretativo por meio desta imagem não me ofereceu nada além de informar que a cena remete ao Getsêmani. Pesquisas em outros livros de arte disponíveis também não contribuíram nesta busca. Vasculhando na internet, encontrei o Getsêmani de Fra Angelico no site www.mycuriosi.com, sob o título ANGELICO, FRA, sob item 3 Florence et Rome, que faz uma apresentação do afresco, que aqui traduzo:

Fra Angelico, o Jardim das Oliveiras. Após o episódio da Ceia, Jesus se rende no jardim de Getsêmani, ao pé do Monte das Oliveiras. Ele pediu que seus discípulos ficassem fora e entrou acompanhado apenas por Pedro, Tiago e João. Enquanto eles dormem, Jesus reza a Deus Pai. Fra Angelico e sua oficina, Jardim das Oliveiras, 1438-1443. Afresco, $177 \times 147$ centímetros. Cela 34, Convento de São Marcos, em Florença.

\footnotetext{
${ }^{4}$ Gadamer (2010, p. 135) chama a atenção para a dificuldade de coadunar as duas questões na ciência da arte, a iconográfica (descrição da imagem) e a questão do conteúdo da imagem, que pode ser compreendido de várias formas, devido à polissemia da imagem e das apreensões possíveis em cada contexto e cultura. As duas dimensões de abordagem, objetiva e subjetiva, fazem parte da hermenêutica da arte e carregam consigo os vários 'prés' interpretativos.
} 
Esta apresentação, que não menciona a presença das mulheres neste afresco de Fra Angelico, remete indiretamente ao conteúdo resumido do texto bíblico no evangelho de Marcos 14,32-42 (ver também textos paralelos de Mateus 26,36-46 e Lucas 22,39-46). Este texto faz parte das narrativas da Paixão que apresentam parte da história de Jesus em Jerusalém, antes de ser crucificado: elas começam com a viagem de Jesus e seu grupo em direção a Jerusalém por ocasião da Páscoa judaica 5 , uma das principais festas religiosas que também era celebrada pelo grupo de Jesus. No caminho, em Betânia, Jesus foi ungido por uma mulher anônima, na casa de um leproso (Mc 14,3-9; Mt 26,6-13), portanto, num gesto sacerdotal realizado por mulher, ele foi reconhecido e confessado rei e messias do povo. ${ }^{6}$ Neste ínterim, é preparada a traição de Jesus pelo apóstolo Judas (Mc 14,10-11.1721), a última ceia de Jesus com seu grupo é realizada (Mc 14,12-16. 22-26), Pedro promete fidelidade (Mc 14,27-31) e, para reconstituir forças e espiritualidade por meio da oração, Jesus e seu grupo se retiram para o lugar nomeado Getsêmani, junto ao Monte das Oliveiras, fora dos muros da cidade de Jerusalém (Mc 14,3242).

Na história da teologia, a oração é tida como marca fundamental da espiritualidade judaico-cristã, por meio da qual a pessoa crente estabelece diálogo com Deus, buscando misericórdia, perdão, consolo e força, além de expressar gratidão e confiança. Por sentir-se angustiado e com medo, Jesus retira-se para orar, e pede ajuda e apoio dos discípulos Pedro, Tiago e João, seus amigos mais próximos: "Fiquem aqui e vigiai!" O perigo é iminente. Judas já havia negociado sua traição-entrega, sendo que a prisão de Jesus poderia acontecer a qualquer instante. Na oração, Jesus apresenta sua vulnerabilidade, sua humanidade diante de seu Deus, que ele chama de $A b a$ - "paizinho": estava cansado, aflito, sofreu desilusão e traição, e pede que este Deus de ternura e cuidado interfira nos acontecimentos - “afasta de mim este cálice”!

\footnotetext{
${ }^{5}$ Acerca da Pessah, ver Sals e Avemarie (2009).

${ }^{6}$ Interpretação e bibliografia em Richter Reimer (2012).
} 
Contudo, enquanto Jesus orava, os três discípulos adormeceram, porque também eles estavam exaustos. Ao lado da oração, também o cansaço é uma característica do movimento itinerante de Jesus7 que, após intens(iv)as incursões de ensino, de cura e de controvérsias com outras tendências político-ideológicas, sempre procurava um lugar para descansar, reclinar a sua cabeça e recompor as energias. Neste contexto de trabalho árduo, a oração e a vigilância serviam para fortalecer a fé, a resistência e o companheirismo/pertencimento, e evidenciavam não apenas a humanidade de Jesus, mas também a de seus seguidores. Do ponto de vista religioso, a oração é uma das expressões da identidade pessoal e grupalcomunitária.

A cena representada por Fra Angelico interpreta pictoricamente o texto de Lucas 22,39-46, porque nela consta também a imagem de um anjo (parte superior esquerda), que não aparece em Marcos e Mateus, mas exclusivamente na narrativa de Lucas $(22,43-44)$ : “apareceu um anjo vindo do céu, fortalecendo-o" (minha tradução do grego; geralmente: “que o servia”). Na imagem frangélica, o anjo traz em sua mão esquerda o cálice e na mão direita, o pão, que já se tornaram sinais eucarísticos a partir do século XII. 8

Para a interpretação, esta é uma referência que também não aparece no texto bíblico; lá apenas consta que um anjo fortalece Jesus. A referência do afresco, portanto, é explícita para a concepção eucarística no contexto histórico e teológico de Fra Angelico, como sacramento que fortalece frente às dificuldades sofridas e que (ainda) devem ser enfrentadas. No mais, a cena reproduz elementos e atributos geográficos e teológicos: o monte, as oliveiras; nos fundos, à direita superior, os muros da cidade de Jerusalém; à esquerda superior, Jesus em oração (já com o atributo da auréola com a cruz purpúrea que remete à ressurreição); no centro, três homens identificados com o nome nas auréolas (São Pedro, São João, São Tiago); à direita inferior, duas mulheres identificadas com o nome nas auréolas (Santa Marta e Santa Maria).

\footnotetext{
${ }^{7}$ Acerca do movimento de Jesus, ver Stegemann e Stegemann (2004).

${ }^{8}$ Le Goff (2008) discorre acerca das importantes transformações eclesiásticas na Idade Média, destacando, entre elas, as doutrinas acerca dos sacramentos para fortalecimento de fé e políticas no contexto de conflitos internos (Inquisição) e externos (avanço do Islã).
} 
Na pintura, a cena é uma só, caracterizada com uma única base / chão dentro de uma só moldura do afresco. Contudo, na cena, o espaço das mulheres é diferenciado com traços retos e côncavos, representando paredes, talvez de uma casa com porta e uma pequena janela. Em termos de cores e luminosidade, as cores destacadas são o bege (chão e paredes) e o purpúreo com verde e branco (vestes), que remetem para a santidade dos personagens, bem como as auréolas. A luz recai mais fortemente sobre as duas mulheres, e em segundo plano também sobre os três homens, enquanto que a penumbra marca a cena da angústia de Jesus. Isto é relevante para a interpretação, pois a luz orienta os olhares para os distintos lugares e personagens, num discurso imagético de (não-)imitação.

\subsection{Focar a imagem: tessituras e releituras}

Para a interpretação da imagem é importante considerar que nenhum dos textos dos evangelhos contém a presença de mulheres na narrativa do Getsêmani, mesmo que se pressuponha, em termos de linguagem, que elas possam estar subsumidas no termo evangélico plural masculino "discípulos". 9 Contudo, o afresco de Fra Angelico apresenta duas mulheres, com auréola e identificação: Santa Marta e Santa Maria. É preciso, pois, não apenas associar o afresco e a imagem com os pressupostos do conhecimento da narrativa e interpretação bíblicas, mas, por meio da hermenêutica de textos e da arte, permitir que aquela narrativa possa "falar uma vez mais" (GADAMER, 2010, p. 136), agora por meio da obra de Fra Angelico.

Em termos de construção da imagem, a base do afresco apresenta um espaço só, sobre o qual se desenrola todo o enredo: o locus é o Jardim do Getsêmani e nele estão representados três grupos de personagens, ou seja, Jesus e o anjo, os três discípulos, Marta e Maria. Este espaço, porém, está diferenciado com o recurso utilizado por Fra Angelico: as formas geométricas retas e abobadadas que inserem ou transferem para aquele lugar outro lugar, ou seja, a casa de Marta e Maria. Elas

\footnotetext{
${ }^{9}$ Em relação à linguagem androcêntrica dos textos bíblicos, no contexto da literatura da época, ver Schüssler Fiorenza (2009).
} 
encontram-se, na interpretação imagética, simultaneamente na casa em Betânia, onde acolheram Jesus (Lc 10,38-39), e no Jardim Getsêmani em Jerusalém, onde Jesus foi ‘abandonado’ por Pedro, Tiago e João.

Portanto, o terceiro grupo de personagens (Marta e Maria) está colocado sobre o mesmo plano (chão) artístico da cena de Jesus e dos discípulos. Nele, a luminosidade maior de Getsêmani está concentrada na cena das mulheres, que se encontram no primeiro plano do afresco. Traços de sua caracterização e de seus atributos encontram-se em oposição à caracterização e aos atributos dos três discípulos: eles dormem, corpos encurvados, rostos apoiados pelas mãos, encontram-se dispersos (cada qual inclinado para uma direção); elas estão acordadas, Marta encontra-se em oração, com as mãos unidas e Maria está lendo, com as mãos sobre o livro. A luminosidade e os atributos querem orientar a atenção para este grupo ‘enxertado’ na cena do Getsêmani evangélico. A pergunta não cala: Por que o monge está destacando isto? O que a imagem quer dizer?

Além destas percebidas diferenças, na cena toda também se percebe que há apenas um elemento que se encontra em consonância com o atributo central de Jesus: as mãos em oração marcam a postura de Jesus e de Marta. Marta representa a mesma postura orante de Jesus! Para o presente da construção daquele afresco, como ainda veremos, isto deve ter tido fundamental importância dentro do contexto histórico-social conturbado da época.

\subsection{Interpretar texto e imagem: mulheres como modelo e desafio históricos}

Em termos iconográficos e interpretativos, a obra de Fra Angelico apresenta uma narrativa bíblica, relendo-a por meio da pintura. A pintura, como os textos, não quer apenas 'descrever' algo que aconteceu, nem quer ser apenas admirada; assim como os textos, ela também objetiva exercer influência sobre quem a 'lê', no sentido de convencer acerca do que 'diz', fazer crer e, assim, intervir na educação, 
nas decisões, nos valores e nas ações de leitores(as). ${ }^{10}$ Nesta perspectiva, imagens são elaborações mentais para comunicar e produzir reações em quem as observa e analisa; agregadas a representações, elas assumem funções para além da mera ilustração e adquirem uma carga discursiva que não apenas testemunha acerca do passado, mas influencia e intervém na forma(ta)ção de mentalidades no presente (PESAVENTO, 2012). Portanto, o Getsêmani não descreve, mas representa algo que precisa ser interpretado para ser compreendido e, para compreender, também é preciso contemplar a obra e com ela dialogar. ${ }^{11}$

A interpretação pictórica de Fra Angelico tem também esta função pedagógica de convencer leitores(as) acerca do que é representado e de captar adesão para o exemplo positivo registrado. Em minha opinião, este exemplo positivo não pôde ser encontrado no grupo dos discípulos escolhidos por Jesus, na cena em questão, e por isto foi ‘enxertado' na cena do Getsêmani por meio da presentificação de Marta e Maria de Betânia que, ao contrário desses discípulos, representam, aqui, o paradigma a ser seguido: elas estão vigilantes, estão orando e se instruindo por meio do estudo. ${ }^{12}$ Como tal, tornaram-se discípulas paradigmáticas não apenas para o tempo passado do movimento de Jesus, mas também para o presente daquele afresco, que pode continuamente ser relido. Observar esta função pedagógica da arte escrita e pintada é tão mais relevante na medida em que considerarmos que as pinturas tinham e têm por público pessoas analfabetas e letradas, e por elas podiam e podem ser 'lidas', interpretadas e compreendidas no sentido da imitatio como indicação que sempre remete a algo mais por intermédio de outras e novas releituras. ${ }^{13}$

\footnotetext{
${ }^{10}$ Sobre esta função pedagógica e prescritiva dos textos e sua interpretação, ver Meneses (2003).

${ }^{11}$ Acerca desta dinâmica interpretativa, ver Gadamer (2010, p. 137).

${ }^{12}$ Levanta-se, aqui, outra pergunta: por que o monge 'enxertou' Marta e Maria e não outras mulheres bíblicas? Uma possível resposta pode ser elaborada a partir do fato de que, na região e no tempo de Fra Angelico, Marta e Maria são santas bastante populares, como mostra a Legenda Áurea (RICHTER REIMER, 2011).

${ }^{13}$ A imitatio no sentido de indicação é "sempre um ato de identificação e, desse modo, de reconhecimento" (GADAMER, 2010, p. 55). A leitura, nesta dinâmica, é um protótipo para a contemplação de obras de arte, com todas as necessárias antecipações e retomadas (pré-compreensão e aprendizagem) que possibilitam apreender o construto ali amalgamado na riqueza articulada de conteúdos da enunciação. A arte observada e analisada nos interpela e 'absorve' e nos insere na obra por meio do diálogo, formando-se aí um jogo de "recíproca participação" (p. 139-40).
} 
A moldura histórica deste afresco encontra-se no palco da virada dos séculos XIV-XV, que marcam uma lenta e longa transição da Idade Média para o Renascimento. Fra Angelico nasceu em 1387, em Vicchio di Mugello, pequena vila na Toscana, próxima a Florença, filho de pai e mãe camponeses, e recebeu o nome de Guido di Pietro. ${ }^{14}$ Com 20 anos de idade, Guido entrou para o convento dominicano de Fiesole, próximo dali, quando adotou o nome de Frei Giovanni, mas já em 1409 se refugiou no convento de Foligno (norte da Itália), devido aos conflitos oriundos do grande cisma da Igreja no Ocidente (1378-1417). Em 1414, a peste obrigou-o a buscar asilo no mosteiro de Cortona, e logo retornou ao convento de origem, em Fiesole, às portas de Florença.

Frei Giovanni, que depois foi chamado de Fra Angelico em homenagem à sua sabedoria e virtudes, despontou em meio a este cenário como teólogo artista, que desenvolveu a arte da pintura desde seu noviciado. Já em 1418, foi encarregado de pintar o altar da capela Gherardini, em Santo Stefano al Ponte, e em 1423 ele pintou a cruz do Hospital de Santa Maria Nuova, em Fiesole. São estas obras iniciais que marcaram sua trajetória artística, que repercutiu e se afirmou intensamente a partir de 1430, tendo por mestre Masaccio, cuja obra muito o influenciou.

Após ter pintado, junto com Benozzo Gozzoli, a convite do papa Nicolau V, seis afrescos na capela Nicolina, no Vaticano, em 1449 Fra Angelico é nomeado prior do Convento dominicano de São Marcos, em Florença e, como tal, não abre mão da pintura (CIVITA, 1978, p. 14), que ali já havia registrado anos antes, assumindo, assim, a vocação de sacerdote pintor também em seu priorado.

Como prior pintor, Fra Angelico continuou buscando, por meio da pintura, cada vez mais uma aproximação pedagógica junto ao povo crente simples. Nesta perspectiva, as cenas da vida de Cristo, também a que está representada no Getsêmani, refletem o tom narrativo de sua obra, com forte acento popular. No fluxo de movimentos de renovação teológico-social (OPITZ, 1990), a tendência

${ }^{14}$ As informações biográficas baseiam em Civita (1978). 
pincelada em suas obras era retornar à vida mais simples e às verdades mais fundamentais da catequese, no caso, a necessidade e o poder da oração e do estudo, mantendo vivas a perseverança e a fé vigilante. Trata-se de uma arte que pode ser 'lida' também por quem não tem muita familiaridade com as artes e, por isto, está mais dirigida às sensibilidades do povo simples e iletrado. "A linguagem do pregador popular que surge das imagens aproxima-se da linguagem que os dominicanos utilizam cada vez mais em seu diálogo com o povo” (CIVITA, 1978, p. 14).

Naquela época, na Itália desenvolveram-se atitudes que impregnaram expressões culturais e artísticas em meio ao clima de violência e injustiça. Na Igreja predominava ainda, em termos doutrinais, o ascetismo, a mortificação da carne e o desapego aos bens terrenos, visto que 'este mundo' era compreendido como lugar de passagem, preparação para a 'outra vida'. Esta forma de vida e doutrina, presente na teologia e na filosofia, passou a ser questionada, mesmo que ainda presente: viver em clausuras e na vida contemplativa, cobrir o corpo com hábitos, confiar mais no céu do que transformar a vida na terra e hostilizar as mulheres começaram a ser perscrutados a partir de outros olhares e perspectivas (LE GOFF, 2008).

Ideais e valores, sociabilidades e sensibilidades da Idade Média começaram a passar por mudanças significativas neste período, na medida em que intelectuais, também mulheres, percebiam que é preciso viver plenamente já agora em meio aos horrores da guerra, da fome, das doenças, das punições. A vida começa a ser contemplada de maneira a prestigiar também as coisas boas, o prazer e o belo. No contexto, é possível perceber Fra Angelico, junto com significativas novas perspectivas, percepções e atuação de mulheres naquele período, como um precursor ou defensor dessa perspectiva, vinculando, como até então comum na Idade Média, o sentido da arte às suas convicções religiosas ${ }^{15}$ : a natureza e o belo, o prazer e a alegria são considerados unicamente como caminho para ascender a

\footnotetext{
${ }^{15}$ Acerca da arte como expressão cristã eclesiástica na Idade Média, ver Frugoni (1990).
} 
Deus, criador de tudo, também da luz, que é forte característica da pintura frangélica, como observado acima na descrição do Getsêmani. A convicção de que Deus tudo criou e que, desde o céu, governava toda ação humana e salvará a humanidade concedeu uma relativa paz ao sacerdote pintor em meio aos tumultos de seu tempo, permitindo que expressasse a mesma por meio de sua arte. Esta paz foi expressa não apenas pela luminosidade, mas também pelos traços humanos dos personagens, como percebido principalmente em Santa Marta e Santa Maria.

\subsection{O Getsêmani e parte da história de mulheres}

Fra Angelico viveu, portanto, numa época em que as realidades conflitivas do grande cisma ocorrido na Igreja do Ocidente, os sofrimentos causados por guerras e pestes, perseguições e morte de 'hereges', abismos socioeconômicos e o avanço dos turcos otomanos sobre Constantinopla marcavam o cenário maior, dentro do qual também a cultura e a arte assumiam espaços para expressar as sensibilidades, realidades e expectativas.

No afresco Getsêmani, parte desta realidade se faz presente na penumbra que representa a angústia de Jesus e na postura orante de Jesus e de Marta que clama por conforto e fortalecimento em meio a situações de sofrimento, perseguição, doença e morte. Simultaneamente, sacramento e estudo remetem para as novidades da época, das quais também mulheres participavam.

Le Goff (2008) chama a atenção para elementos positivos possibilitados por estruturas eclesiais às mulheres nesse período, como o acesso ao estudo nas escolas e a participação igualitária nos benefícios oferecidos pelos sacramentos. Encontramo-nos frente a realidades de significativas luzes em meio ao longo período medieval, que foram pinceladas também pelas cores e texturas de Fra 
Angelico e por escritos de mulheres na mesma época e anterior à mesma. ${ }^{16}$ Estes escritos precederam e eram contíguos à obra de Fra Angelico, cobrindo praticamente todo o território europeu. Mulheres adentravam a vida religiosa, tornavam-se sujeito teológico e hermenêutico, atuavam em todas as esferas profissionais e colocavam sua vida em confronto com a história interpretativa misógina que se perpetuava no trabalho teológico eclesiástico. Tornaram-se estudantes, mestras, pregadoras, escritoras, monjas, abadessas.

Trata-se de um período de "profunda inquietação religiosa" (OPITZ, 1990, p. 424), no qual cada vez mais mulheres de todos os estratos sociais, no exercício de todas as formas de trabalhos e profissões, criavam e se inseriam em movimentos de renovação, visando uma vida ativa e contemplativa apostólicas, buscando romper com tradicionais marcas misóginas ${ }^{17}$. Apesar do imaginário ainda permeado por construções misóginas e patriarcais, que legitimavam e faziam prevalecer violências, guerras e injustiças, mulheres ousaram ${ }^{18}$ quebrar silenciamentos e discriminações, adentrando esferas públicas em vários setores, também eclesiais, questionando preconceitos de gênero e de classe. ${ }^{19}$

Neste contexto, há que se observar que, em Getsêmani, Fra Angelico interpreta parte da narrativa da Paixão de Jesus junto com a narrativa de Lucas 10, não apenas interpretando a diaconia de Marta como ativa oração intercessora, mas também pintando Maria debruçada sobre um livro. No texto bíblico, Maria havia

\footnotetext{
16 Lembre-se, por exemplo, que em 1429, em Veneza, foi escrito um poema em homenagem e para memória de Joana d'Arc pela escritora Christine de Pisano. A mesma autora havia escrito, em 1404, O livro da cidade das mulheres em forma de debate entre quatro mulheres (ela própria, dona Razão, dona Retidão e dona Justiça) acerca das injustiças e das experiências misóginas sofridas por mulheres, indicando para uma série de contradições socioeclesiais existentes no início do século XV. Outra autora que escreveu na época foi a abadessa Isabel de Vilhena (1430-90), que influenciou grupos não apenas monásticos com sua interpretação meditativa da Vita Christi, afirmando a importância e centralidade das mulheres no ministério e da vida de Jesus. Denuncia, com Maria de Nazaré e Maria Madalena, ataques misóginos e defende as mulheres de todos os tempos em suas capacidades intelectuais e espirituais. Mais informações sobre mulheres escritoras na História e nas Artes, ver Forcades i Vila (2013) e Frugoni (1990); acerca do trabalho realizado por mulheres em todos os setores, ver Opitz (1990) e Martins (2012).

${ }^{17}$ Ver, a este respeito, várias abordagens apresentadas em Opitz (1990), Forcades i Vila (2013) e Régnier-Bohler (1990).

${ }^{18} \mathrm{Em}$ vários textos de Christine de Pisano, p.ex., ela utiliza a expressão "ousar", referindo-se a si mesma para destacar perigos e rupturas com a documentação e a história interpretativa androcêntrico-patriarcal, como presente também no escritor Filipe de Novara, seu contemporâneo: "A uma mulher não se deve ensinar as letras nem a escrever", pois "a palavra das mulheres letradas deixará durante muito templo aflorar o temor das audácias e o medo das impotências" (RÉGNIER-BOHLER, 1990, p. 536).

${ }^{19} \mathrm{Na}$ busca pela reconstrução da vida apostólica, vários grupos e movimentos de mulheres foram se organizando em torno de vivência de fé e espiritualidade com repercussão em nível social. Ver Opitz (1990), Frugoni (1990), Régnier-Bohler (1990) e Le Goff (2008, p. 117ss.) que apresentam, de maneiras diversas, esta atuação de mulheres em praticamente todos os setores no final da Idade Média.
} 
sido representada como discípula que aprende aos pés do mestre Jesus, postura característica no judaísmo da época para representar a relação mestrediscípulo(a)20. Na interpretação pictórica frangélica, o discipulado de Maria se faz representar por meio do aprendizado e do estudo das Escrituras, fazendo jus ao fato de que, naquela época, mulheres estavam não apenas tendo acesso à alfabetização e à instrução, mas também estavam escrevendo e ensinando, como mostram os trabalhos acima referidos da abadessa Isabel de Vilhena e Christine de Pisano e várias obras artísticas ${ }^{21}$. Marta, por seu turno, que, no texto bíblico está representada como discípula diácona, concretiza esta diaconia, nas pinceladas do sacerdote pintor, por meio da mesma função de Jesus: com a oração, ela tornou-se intermediária dos clamores do povo.

Assim, com esta obra de Fra Angelico e manifestações teológicas escritas por mulheres nesse mesmo período, percebo significativos indícios para uma mudança na história interpretativa de Lucas 10. Nela, geralmente as irmãs Marta e Maria eram apresentadas, num constructo marcadamente dualista, como antagonistas, sendo utilizadas por teólogos para construir e sedimentar a ideia patriarcal de estereótipos femininos dicotômicos que distinguiam rigidamente entre as esferas domésticas (Marta) e meditativas (Maria), entre mulheres 'ativas' e 'passivas', entre privado e público. ${ }^{22}$ Trata-se de representações femininas arquetípicas que ajudaram a forma(ta)r os princípios básicos da sociedade patriarcal e cristã, na qual, de acordo com Amparo (2013), a mulher passou a oscilar entre dois perfis bem distintos (sacro e profano) e dois estados básicos neoplatônicos (ativo e contemplativo).

É interessante observar que esta interpretação começa a ser questionada já no século XIII, dentro e a partir do crescente movimento de mulheres. Trata-se, por exemplo, da interpretação de Lc 10 feita por Mestre Eckhart, monge

\footnotetext{
${ }^{20}$ Ver discussão exegética em Richter Reimer (2011), com bibliografia.

${ }^{21}$ Ver, p.ex., imagens e informações em Frugoni (1990, principalmente p. 493ss.).

22 Esta história interpretativa é representativa para a Patrística e foi introduzida por Orígenes em suas Homilias de Lucas em perspectiva dualista que situa o nível espiritual (vida contemplativa) acima do corporal (vida ativa), a teoria acima da práxis. Esta chave hermenêutica para o texto de Lc 10 continuou sendo desenvolvida por teólogos como Basílio de Cesareia, Evagrius Ponticus e João Cassiano num constructo dualista que afirmava que Marta tinha um 'pequeno e imperfeito carisma' e Maria, um 'grande e perfeito'. Maiores informações e exemplos, ver Richter Reimer (2011) e, acerca dos imaginários misóginos, Dalarun (1990).
} 
dominicano, filósofo místico, que se tornou vítima da Inquisição, acusado de cometer heresia: ele afirmava a importância equitativa de Marta e Maria por meio de sua fé madura que se expressava na diaconia e no discipulado. ${ }^{23}$ Esta percepção contribuiu para a formação de comunidades religiosas, nas quais mulheres eram lideranças, engendrando outro tipo de mulher medieval, cuja vida religiosa devia ser caracterizada por seguimento a Cristo (não a outras autoridades), desapego aos bens e amor ao próximo.

Com sua arte interpretativa e no espírito vanguardista que lhe precedia e acompanhava, o dominicano Fra Angelico continuou pincelando traços contra o fluxo majoritário daquela história interpretativa que se impregnara no imaginário: ele colocou Marta e Maria, juntas e lado a lado, como discípulas fiéis e vigilantes na cena do Getsêmani; não deixou que Marta continuasse 'correndo para lá e para cá' atrás de tantos serviços e a tornou representante da espiritualidade orante, e apresentou Maria como estudiosa da Bíblia. São estas três características (discipulado fiel e vigilante; espiritualidade orante; estudo e ensino da Bíblia) que marcaram, na perspectiva frangélica, a santidade destas mulheres bíblicas naquele período da Idade Média ${ }^{24}$, servindo de modelo positivo para mulheres e homens de seu tempo. Era necessário redirecionar o olhar, reestruturar as dinâmicas da vida e das relações.

Assim, com este afresco e por meio do trabalho interpretativo,

acontece paradigmaticamente aquilo que todos nós fazemos na medida em que estamos aqui: estruturação constante do mundo [...] e talvez todas as forças de conservação e manutenção que sustentam a cultura humana repousem sobre aquilo que vem ao nosso encontro de maneira exemplar no fazer dos artistas e na experiência da arte: o fato de sempre ordenarmos uma vez mais aquilo que nos decompõe (GADAMER, 2010, p. 23).

\footnotetext{
${ }^{23}$ A contribuição de Mestre Eckhart está bem explicitada em Moltmann-Wendel (1982).

${ }^{24} \mathrm{Na}$ história da Igreja, o final da Idade Média registrou o maior número de mulheres canonizadas, solteiras, mães, viúvas que participaram ativamente deste tempo de 'profunda inquietação religiosa', participando de todos os níveis de relações sociais, políticas e teológicas. Em grupos e comunidades, buscando reconstruir valores apostólicos, empenhavam-se também na luta contra a pobreza e a ignorância. Seu crescente interesse pelos estudos teológicos e seu trabalho na elaboração de prática e textos místicos suscitavam não apenas adesão, mas também desconfiança e perseguição por parte de autoridades político-eclesiásticas. Assim, também nesse período, a história de mulheres foi caracterizada por emancipação e repressão, valorização e depreciação. Ver Opitz (1990, p. 422ss.).
} 
Com estas in(ter)ferências no imaginário religioso acerca de Marta e Maria, o Getsêmani de Fra Angelico deve ter dialogado profundamente com os desafios de seu tempo, enfatizando e influenciando também a experiência de mulheres na apropriação de cultura e história por meio da alfabetização, leitura, estudo de textos clássicos, entre eles as Escrituras, bem como sua manifestação por meio da escrita teológica e meditativa e por meio de debates e pregações. A obra, portanto, não apenas registra, mas também deixa um legado de empoderamento para mulheres daquela e de outras épocas.

\section{Observações finais}

Por fim, pode-se observar ainda que as cenas pintadas por Fra Angelico nos afrescos nas celas do convento de São Marcos tornaram-se referencial para a arte deste período: aos poucos desaparecem os traços do naturalismo religioso e passase a constituir outras propostas de temas para a meditação dos monges e a instrução das mulheres e do povo em geral (CIVITA, 1978, p. 10).

$\mathrm{Na}$ arte frangélica, a busca pelo espaço concebido como lugar ideal manifesta-se também nos traços geométricos, marcados pela luminosidade intensa e deslumbrante que cria a sensação de algo sobrenatural, tremendo e fascinante, como representado em Getsêmani. Neste sentido, sua pintura é um contributo para a arte renascentista não só para análises das relações entre luz e cor, formas e espaços, mas também em relação aos estudos da natureza, peculiaridades humanas e história das mulheres.

Esta arte e espiritualidade estão presentes na capela de São Marcos e marcam um dos pontos altos da expressão artística do sacerdote artista. Nela, a acolhida, o amor e a ternura de Deus se expressam como contrapartida à injustiça e violência vividas naquela época, representadas em sua arte por meio de traços e cores marcados por penumbra e escuridão, vencidas, contudo, por meio da diaconia consoladora do anjo em relação a Jesus, da oração de Jesus e de Marta e do estudo de Maria. Tais expressões de cultura, de espiritualidade e santidade são 
propostas de Fra Angelico para combater as agruras daquele tempo, que podem ser relidas e reinterpretadas também em outros tempos.

O sacerdote pintor faleceu em 18 de fevereiro de 1455, no convento de Santa Maria, em Roma, após ter pintado, a partir de 1453, os protomártires na capela Nicolina. No todo, Fra Angelico

expressa uma síntese insuperável da transição do espiritualismo medieval [...ao] mundo renascentista. Viveu num tempo em que o primeiro debatiase em estertores agônicos, e se prolongava em não poucas consciências, e o segundo entrava com passos vacilantes, mas cada vez mais seguros à medida que iam prosseguindo, na arena da arte e da vida social. [...] sua obra é testemunho de um momento fascinante da aventura humana [...numa] sociedade que começava a compreender que o destino do homem não devia identificar-se forçosamente com a mortificação, com a frugalidade, com a vida austera e recolhida (CIVITA, 1978, p. 19-20).

Para uma história de mulheres em perspectiva feminista, que contribua para empoderamentos e transformações possíveis em cada período histórico, o contributo aqui vislumbrado pode, certamente, colocar sinais que ajudam a perceber também a 'idade das trevas' com brechas para luzes que nunca deixaram de existir e brilhar. Apesar das realidades históricas da misoginia, na vida e nas ciências, mulheres participa(va)m dos avanços, das demandas e dos trabalhos necessários para realização de uma vida digna e justa, o que ficou registrado, no Getsêmani, com Marta e Maria como modelo positivo de fé e santidade. Nesta perspectiva, Fra Angelico pode ser entendido como representante de mulheres que atuavam nos movimentos e comunidades de renovação religioso-sociais de seu tempo, numa junção de vida contemplativa e ativa, de oração e ação, de estudo e ensino.

Em perspectiva de história interpretativa, Marta e Maria permanecem protagonistas no movimento de Jesus, apresentando algumas formas possíveis de seguimento e discipulado. A 'reserva de sentido' hermenêutica desafia as ciências e as artes hodiernas para reler esta narrativa em nossos contextos, conferindo-lhe 
sentido em outras situações e condições que demandam outras aproximações, in(ter)ferências, (re)organizações e realizações. Assim, a letra pode se tornar reiteradamente viva e portadora de vida.

\section{REFERÊNCIAS}

AMPARO, Flávia Vieira da Silva do. O êxtase de Teresas: o sacro e o profano na Literatura e nas Artes. Horizonte, Belo Horizonte, v. 11, n. 31, p. 843-866, jul./set. 2013.

ANGELICO, Fra. s/d. Présentation. Disponível em:

http://www.mycuriosi.com/documentation1/angelico.html. Acesso em: 16 maio 2014.

CIVITA, Victor (Ed.). Mestres da Pintura: Fra Angelico (1387-1455). 1. ed. São Paulo: Abril S.A.Cultural e Industrial, 1978 [1967 Roma].

DALARUN, Jacques. Olhares de clérigos. In: DUBY, Georges; PERROT, Michelle (Org.). História das Mulheres no Ocidente. v. 2: A Idade Média, sob direção de Christiane Klapisch-Zuber. Tradução de Ana Losa Ramalho et al. Porto: Afrontamento, 1990. p. 2963.

FORCADES I VILA, Teresa. La teologia feminista en la história. Barcelona: Presente, 2013.

FRUGONI, Chiara. A mulher nas imagens, a mulher imaginada. In: DUBY, Georges; PERROT, Michelle (Org.). História das Mulheres no Ocidente. v. 2: A Idade Média, sob direção de Christiane Klapisch-Zuber. Tradução de Ana Losa Ramalho et al. Porto: Afrontamento, 1990. p. 461-511.

GADAMER, Hans-Georg. Hermenêutica da Obra de Arte. Seleção e tradução de Marco Antonio Casanova. São Paulo: Martins Fontes, 2010.

LE GOFF, Jacques. Uma longa Idade Média. Tradução de Marcos de Castro. Rio de Janeiro: Civilização Brasileira, 2008.

MARTINS, Ana Paula Vosne. Duas honestas cortesãs do renascimento italiano:interseções da cultura humanista, da escrita de mulheres e da sexualidade no século XVI. ArtCultura, Uberlândia, v. 14, n. 25, p. 185-199, jul.-dez. 2012.

MENESES, Ulpiano T. Bezerra de. Fontes visuais, cultura visual, História visual: balanço provisório, propostas cautelares. Revista Brasileira de História, São Paulo, v. 23, n. 45, p. 11-36, 2003.

MOLTMANN-WENDEL, Elisabeth. Ein eigener Mensch werden: Frauen um Jesus. Gïtersloh: Gütersloher Verlagshaus, 1982. 
OPITZ, Claudia. O quotidiano da mulher no final da Idade Média (1250-1500). In: DUBY, Georges; PERROT, Michelle (Org.). História das Mulheres no Ocidente. v. 2: A Idade Média, sob direção de Christiane Klapisch-Zuber. Tradução de Ana Losa Ramalho et al. Porto: Afrontamento, 1990. p. 353-435.

PESAVENTO, Sandra. História e História Cultural. 3. ed. Belo Horizonte: Autêntica, 2012.

RÉGNIER-BOHLER, Danielle. Vozes literárias, vozes místicas. In: DUBY, Georges; PERROT, Michelle (Org.). História das Mulheres no Ocidente. v. 2: A Idade Média, sob direção de Christiane Klapisch-Zuber. Tradução de Ana Losa Ramalho et al. Porto: Afrontamento, 1990. p. 517-591.

RICHTER REIMER, Ivoni. Compaixão, cruz e esperança: teologia de Marcos. São Paulo: Paulinas, 2012.

RICHTER REIMER, Ivoni. Marta e Maria: cozinha, seara e dragões?! Discípulas de Jesus, interpretações e releituras. In: PERETTI, Clélia (Org.). Filosofia do gênero em face da Teologia: espelho do passado e do presente em perspectiva do amanhã. Curitiba:

Champagnat Ed. PUCPR, 2011. p. 223-250.

RO SEROUGE. Da inteligência das mulheres (2010). Disponível em: <http://absolutely-roserouge.blogspot.com.br/2010/o5/da-inteligencia-dasmulheres.html>. Acesso em: 20 jun. 2014.

SALS, Ulrike; AVEMARIE, Friedrich. Art. Feste. In: CRÜSEMANN, Frank et al.

Sozialgeschichtliches Woerterbuch zur Bibel. Güetersloh: Güterloher Verlagshaus, 2009. p. 137-143.

SCHÜSSLER FIORENZA, Elisabeth. Caminhos de Sabedoria: uma introdução à interpretação bíblica feminista. Tradução de Monika Ottermann. São Bernardo do Campo: Nhanduti, 2009.

STEGEMANN, Ekkehard W.; STEGEMANN, Wolfgang. História social do protocristianismo: os primórdios no judaísmo e as comunidades de Cristo no mundo mediterrâneo. Tradução de Nélio Schneider. São Leopoldo: Sinodal; São Paulo: Paulus, 2004. 